\title{
ANATOMIA DESCRITIVA DA MADEIRA DE QUEBRACHO-BRANCO (Aspidosperma quebracho-blanco Schlecht.).
}

Josē Newton Cardoso Marchiori

Departamento de Ciências Florestais. Centro de Ciēncias Rurais. UFSM. Santa Maria, RS.

RESUMO

São descritos os caracteres gerais, macroscópicos e micros cōpicos da madeira de Aspidosperma quebracho-blanco Schlecht. São fornecidos dados quantitativos e histométricos, bem como fotomicro grafias da madeira.

SUMMARY

MARCHIORI, J.N.C. Descriptive wood anatomy of quebracho-branco (As pidosperma quebracho-blanco Schlecht.). Ciência e Natura, $7: 99-106$.

The gross, macroscopic and microscopic wood structure of Aspidosperma quebracho-bzanco Schlecht. are described. The quantita tive and histometric secondary xylem data obtained, as well as photo micrographs of the wood, are also furnished.

\section{INTRODUÇÃO}

0 gênero Aspidosperma Mart. et Zucc., da famīlia Apocynaceae Lindl., reūne cerca de 70 espēcies de ārvores pequenas, de tamanho médio e atē grandes, dispersas largamente e de maneira descontīnua na América tropical, notadamente nas regiões mais secas da América do Sul (RECORD \& HESS, 7 ).

A flora brasileira é rica em espécies de Aspidosperma, al gumas das auais tem grande importância pela produção de madeiras no bres. No sul do País o gênero é fracamente representado, havendo, segundo MARKGRAF (4) apenas quatro espécies em Santa Catarina. Des tas, somente $A$. australe Müll. Arg. e A. olivaceum Müll. Arg. são, de acordo com REITZ et al. (8), nativas no Rio Grande do Sul.

A literatura botānica não faz referēncias sobre a ocorrēn cia de Aspidosperma quebracho-blanco Schlecht. no Rio Grande do Sul. A presença desta ārvore no Estado ē de conhecimento recente, tendo sido encontrada pelo autor nos arredores de Barra do Quarai, munici pio de Uruguaiana, associada em vegetação de tipo Parque comprosopis nigra (Gris.) Hieron., Parkinsonia aculeata L., Acacia caven (Mol.) Mol. e Prosopis algarobizza Gris.

TORTORELLI (10) considera o quebracho-branco como uma das espēcies características da zona ocidental seca do Parque Chaquenho. MARZOCCA (5) refere a espēcie como indígena do Paraguai, Uruguai e 
Argentina. Neste País, e segundo o mesmo autor, encontra-se desde 0 1 imite norte até as Províncias de Santa Fé e Córdoba, abarcando o Parque Mesopotâmico, quase todo o Parque Chaquenho e estendendo - se atē a região central do Monte Xerófilo. No Uruguai, é encontrada às margens do rio homónimo, nos Departamentos de Paysandú, Salto e Ar tigas ( LOMBARDO, 3).

0 quebracho-branco è ārvore de até 20 metros de altura e $80 \mathrm{~cm}$ de diâmetro, com tronco esbelto e reto, casca amarelo-acinzen tada muito rugosa e com fendas longitudinais profundas de cor tenden te ao ocre. Tem folhagem perene, folhas geralmente em verticilos de 3 , raramente opostas; simples, glabras, coriāceas, elíptico-lan ceoladas, de atē $5 \mathrm{~cm}$ de comprimento e mais ou menos $1,2 \mathrm{~cm}$ de largura, pe ninervadas e com nervura central bem visível, com āpice terminando em espinho, bordo inteiro e base atenuada, decurrente em pecỉolo muito curto. As flores são pequenas, de cor ocre e dispostas em pa nïculas (TORTORELLI, 10). Os frutos são cāpsulas lenhosas achatadas, de forma orbicular, oval ou elíptica, verde-acinzentadas e pubescen tes externamente, com normalmente $7-9 \mathrm{~cm}$ de comprimento por $5-6 \mathrm{~cm}$ de largura e 1-2 cm de espessura; sementes aladas, com asa membrano sa mais ou menos circular (TORTORELLI, 9).

A madeira tem mūitiplas utilidades. Na Argentina ē usada na fabricação de carvão vegetal, possuindo poder calorífico de 3.600 a $4.000 \mathrm{Kcal} / \mathrm{Kg}$. (LATZINA, 2); na indūstria de mōveis, fabricação de ferramentas, como postes de cerca e madeira de interior em constru ções (MARZOCCA, 5). TORTORELLI (10) aconselha seu uso, após trata mente preservativo, como dormentes de ferrovias, em virtude da boa resistência da madeira e abundāncia de ārvores no paîs.

Por ser espécie nativa, produtora de madeira de boa quali dade e praticamente desconhecida no Rio Grande do Sul, torna-se im portante a realização de estudos com esta essência florestal, nota damente sobre seus aspectos silviculturais no Estado. No presente trabalho são descritos os caracteres estéticos, macroscópicos e mi croscōpicos da madeira.

\section{REVISÃO DA LITERATURA ANATŌMICA}

Em Aspidosperma sp. observa-se uma grande diversidade com relação aos caracteres anatômicos da madeira. De acordo com METCAL FE \& CHALK (6), as espécies diferem entre si, mais do que o comum dentro de um gênero.

METCALFE \& CHALK (6) referem a presença de poros pequenos ou de diāmetro médio, esclusivamente solitários, com frequência in ferior a 5 poros $/ \mathrm{mm}^{2}$ e presença de tiloses em certas espécies; plá cas de perfuração simples e tipicamente pequenas em relação ao diâa metro dos vasos; pontuações intervasculares em arranjo alterno, mui 
to pequenas a diminutas e ornamentadas; pontuações parēnquimo-vas culares e rádio-vasculares semelhantes às intervasculares; parênqui ma axial tipicamente apotraqueal, mas tambēm paratraqueal escasso e em faixas terminais; raios de atē 4-6 células de largura, heterogé neos e freqüentemente com mais de 3 fileiras marginais de células eretas ou quadradas, ou então quase homogêneos e com poucos ou mode radamente numerosos raios uni-seriados; e fibras de parede moderada mente espessa, com pontuações tipicamente areoladas e mais frequen temente dispostas nas faces radiais da parede.

RECORD \& HESS (7) descrevem a madeira de quebracho-branco como muito dura e pesada, flexível, forte e resiliente, bastante di fícil de trabalhar mas tomando acabamento liso, com peso especifico seco ao ar entre 0.80 e 1.00 , e cerne não nitidamente diferenciado do alburno, de cor amarelada ou marrom-rosado, algumas vezes com va riegado que desaparece gradualmente mediante exposição ao ar.

TORTORELLI $(9 ; 10)$ fornece uma descrição anatōmica, bem co mo caracteres físico-mecânicos da madeira de Aspidosperma quebracho -bZanco. Da descrição microscōpica merecem destaque a presença de apēndices vasculares longos em elementos vasculares curtos a media nos $(93-253-434 \mu \mathrm{m})$; poros de diâmetro mēdio (80 - $160-240 \mu \mathrm{m})$, tipicamente solitārios e de forma oval a elīptica; fibras de 900 $1200 \mu \mathrm{m}$ de comprimento, libriformes em sua maioria mas tambēm com fibrotraqueōides de pontuações areoladas muito pequenas; raios lenho sos em nūmero de 8 a 10 por mm, predominantemente tri-seriados, ho mogêneos ou com margem uni-seriada de cēlulas eretas e quadradas; anéis de crescimento pouco demarcados; e parēnquima lenhoso com ten dência a reticulado.

MATERIAL E METODOS

0 material estudado consiste da amostra de madeira no 309 e exsicata nọ 591, depositada na Xiloteca e Herbārio do Departamen to de Ciências Florestais da UFSM. O material foi coletado de uma ārvore adulta, por Marchiori \& Longhi, em 02/7/1982, prōximo à Bar ra do Quaraí, municīpio de Uruguaiana, RS.

Da amostra de madeira foram obtidos três bloquinhos, orien tados para a realização de cortes anatômicos nos planos transversal, longitudinal-radial e longitudinal-tangencial. Os bloquinhos foram amolecidos por fervura em àgua e cortados em micrótomo de deslize, tendo sido obtidas vārias lâminas de cada plano anatômico, com es pessura nominal variāvel entre 16 e $20 \mu \mathrm{m}$. Usou-se coloração com sa franina e azul-de-astra, e montagem permanente com "entellan".

$\mathrm{Na}$ maceração de palitos de madeira usou-se solução em par tes iguais de àcido nîtrico 10\% e ācido crōmico 10\%. As lâminas de tecido dissociado receberam apenas coloração de safranina. 
Para a descrição anatômica foram realizadas as medições recomendadas pela COPANT (1). Os dados quantitativos e estereológi cos são apresentados na Tabela I.

TABELA I. Dados quantitativos e estereológicos da estrutura anatōmi ca da madeira de Aspidosperma quebracho-blanco Schlecht.

\begin{tabular}{|c|c|c|c|c|}
\hline CARACTERISTICA & $\begin{array}{l}\text { VALOR } \\
\text { MIN. }\end{array}$ & MEDIA & $\begin{array}{c}\text { VALOR } \\
\text { MĀX. }\end{array}$ & $\begin{array}{l}\text { DESVIO } \\
\text { PADRAO }\end{array}$ \\
\hline 1. Fração poros (\%) & 4,0 & 7,1 & 10,0 & 2,29 \\
\hline 2. Frequência de poros (poros $/ \mathrm{mm}^{2}$ ) & 17,0 & 29,3 & 46,0 & 8,16 \\
\hline 3. $\emptyset$ de poros solitārios ( $\mu \mathrm{m})$ & 27,5 & 57,1 & 92,5 & 14,89 \\
\hline 4. E. parede de poros $(\mu \mathrm{m})$ & 1,8 & 2,9 & 3,8 & 0,58 \\
\hline 5. C. de elementos vasculares $(\mu \mathrm{m})$ & 207,5 & 360,1 & 525,0 & 71,33 \\
\hline 6. C. apêndices de elementos vasculares $(\mu \mathrm{m})$ & 12,5 & 59,6 & 205,0 & 43,30 \\
\hline 7. $\emptyset$ pontuações intervasculares $(\mu \mathrm{m})$ & 3,5 & 3,9 & 4,5 & 0,33 \\
\hline 8. $\emptyset$ pontuações rádio-vasculares $(\mu \mathrm{m})$ & 2,5 & 3,3 & 4,0 & 0,43 \\
\hline 9. $\emptyset$ pontuações parênq.-vasculares $(\mu \mathrm{m})$ & 3,0 & 3,6 & 4,0 & 0,30 \\
\hline 10. Fração parênquima axial (\%) & 12,0 & 15,9 & 24,0 & 3,68 \\
\hline 11. H. séries parênquima axial $(\mu \mathrm{m})$ & 245,0 & 353,9 & 480,2 & 55,50 \\
\hline 12. H. sēries parênquima axial (células) & 2,0 & 3,0 & 6,0 & 0,69 \\
\hline 13. H. células parênq. axial seriado $(\mu \mathrm{m})$ & 52,5 & 99,3 & 175,0 & 24,63 \\
\hline 14. L. células parênq. axial seriado $(\mu \mathrm{m})$ & 8,8 & 16,7 & 28,7 & 4,12 \\
\hline 15. Fração raios (\%) & 19,0 & 22,2 & 26,0 & 2,60 \\
\hline 16. Fração raios uni-seriados (\%) & 1,0 & 3,3 & 5,0 & 1,38 \\
\hline 17. H. raios uni-seriados $(\mu \mathrm{m})$ & 20,0 & 72,9 & 125,0 & 25,98 \\
\hline 18. H. raios uni-seriados (células) & 1,0 & 3,5 & 6,0 & 1,43 \\
\hline 19. L. raios uni-seriados $(\mu \mathrm{m})$ & 7,5 & 13,2 & 20,0 & 2,83 \\
\hline 20. Fração raios 2-seriados (\%) & 9,0 & 13,1 & 19,0 & 3,09 \\
\hline 21. Fração raios 3-seriados (\%) & 60,0 & 67,9 & 75,0 & 5,86 \\
\hline 22. Fração raios 4-seriados (\%) & 10,0 & 15,7 & 22,0 & 4,49 \\
\hline 23. Frequência de raios (raios/mm) & 8,0 & 10,8 & 14,0 & 1,39 \\
\hline 24. H. raios multi-seriados $(\mu \mathrm{m})$ & 130,0 & 276,4 & 515,0 & 88,37 \\
\hline 25. H. raios multi-seriados (células) & 6,0 & 15,4 & 31,0 & 5,29 \\
\hline 26. L. raios multi-seriados $(\mu \mathrm{m})$ & 15,0 & 37,3 & 50,0 & 9,17 \\
\hline 27. L. raios multi-seriados (cēlulas) & 2,0 & 3,0 & 4,0 & 0,53 \\
\hline 28. Fração fibras (\%) & 48,0 & 54,8 & 61,0 & 4,33 \\
\hline 29. C. de fibras $(\mu \mathrm{m})$ & 735,0 & 1125,2 & 1362,2 & 151,18 \\
\hline 30. $\emptyset$ de fibras ( $\mu \mathrm{m})$ & 11,3 & 14,7 & 22,5 & 2,12 \\
\hline 31. $\emptyset$ do lümem de fibras ( $\mu \mathrm{m})$ & 1,3 & 4,5 & 7,5 & 1,91 \\
\hline 32. E. parede de fibras $(\mu \mathrm{m})$ & 4,3 & 5,2 & 6,9 & 0,70 \\
\hline
\end{tabular}

As fotomicrografias da Figura 1 foram tomadas em aparelho Carl Zeiss, do Departamento de Morfologia da UFSM. 

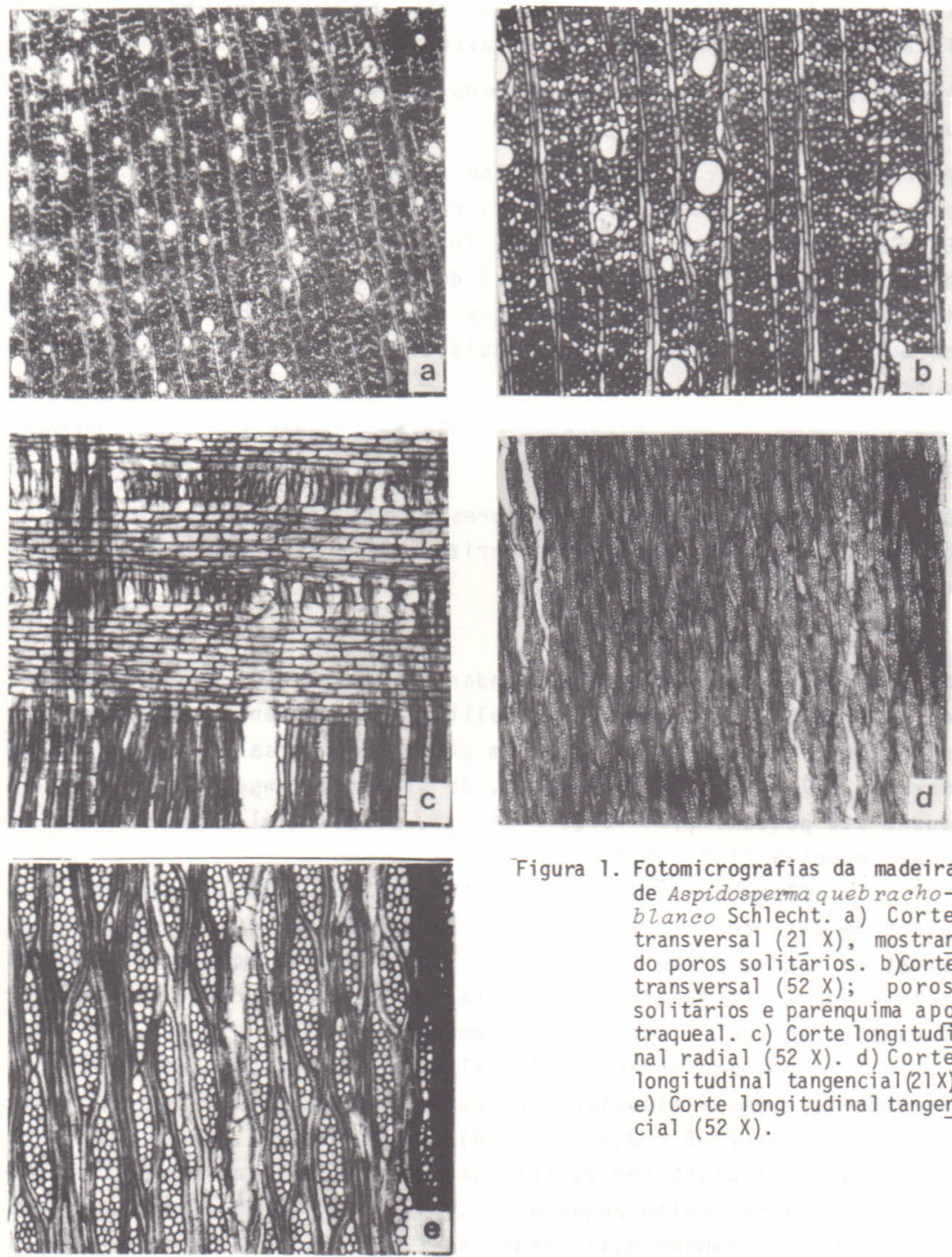

Figura 1. Fotomicrografias da madeira de Aspidosperma quebrachobranco Schlecht. a) Corte transversal (21 X), mostran do poros solitários. b)Cortē transversal (52 X); poros solitários e parênquima apo traqueal. c) Corte longi tudí nal radial (52 X). d) Corte longitudinal tangencial (21 X). e) Corte longitudinal tangen cial $(52 \mathrm{X})$.

DESCRIÇAO DA MADEIRA

CARACTERES GERAIS E ORGANOLEPTICOS

Madeira de cerne e alburno indistintos, de cor amarelo-pa Iha, de brilho suave, grã cruzada revessa, macia ao corte em nava lha, de textura fina e sem odor e sabor característicos.

CARACTERES MACROSCOPICOS

Poros: Invisĩveis a olho nū, visỉveis sob lente de $10 \times$ em plano 
transversal, pequenos, pouco frequentes, em distribuição uniforme,so litários e sem conteúdo. Linhas vasculares retilîneas, sem conteúdo. Parênquima axial: Invisivel em plano transversal, mesmo com lente ou lupa de $10 \mathrm{X}$.

Parênquima radial: Invisível a olho nú em plano transversal, visivel sem dificuldade sob lente de $10 \mathrm{X}$; raios finos, pouco frequentes. Em plano longitudinal tangencial, invisíveis a olho nú e sob lente de $10 \mathrm{X}$. 0 pouco contraste natural de cor entre os tecidos componen tes do lenho, conferem à madeira um desenho pouco marcado, em que se destacam apenas as linhas vasculares. Espelhado dos raios pouco contrastado.

Anéis de crescimento: Distintos, individualizados por zonas fibrosas tangenciais mais escuras.

outros caracteres: Canais secretores axiais, máculas medulares, 1 í ber incluso, canais secretores horizontais e listrado de estratifi cação, ausentes.

\section{CARACTERES MICROSCOPICOS}

Vasos: Tecido vascular pouco abundante $(7,1 \%$ da secção transversal da madeira), formado por poros solitários, raramente geminados, em distribuição difusa e uniforme em plano transversal. Poros muito nu merosos $\left(17-29-46\right.$ poros $\left./ \mathrm{mm}^{2}\right)$, de diâmetro tangencial muito pé queno até pequeno $(17-29,3-46 \mu \mathrm{m})$, seç̧ão oval e parede celular pouco espessa $(1,8-2,9-3,8 \mu \mathrm{m})$.

Elementos vasculares curtos $(207,5-360,1-525 \mu \mathrm{m})$, com placa de perfuração simples e mais comumente oblíqua ao vaso, despro vidos de ornamentação nas paredes, sem conteúdos em lâminas permanen tes, e com apēndices frequentemente longos (12,5 - 59,6 - 205 $\mu \mathrm{m})$, presentes em uma ou em ambas extremidades.

Pontuado intervascular alterno, de díficil observação em virtude da escassa associação de poros. Pontuações intervasculares muito pequenas $(3,5-3,9-4,5 \mu \mathrm{m})$, de forma oval, e com abertura inclusa, lenticular, horizontal, não guarnecida. Pontuações parēn quimo-vasculares muito pequenas $(3,0-3,6-4,0 \mu \mathrm{m})$; pontuações ráa dio-vasculares tambêm muito pequenas $(2,5-3,3-4,0 \mu \mathrm{m})$ e ovala das, semelhantes às intervasculares.

Parênquima axial: Pouco abundante (12 - 15,9 - $24 \%$ da secção trans versal da madeira), em disposição apotraqueal difusa e sub-agregada; formada de sēries parenquimáticas com $2-4$ - 6 cēlulas e $245-353,9$ $480,2 \mu \mathrm{m}$ de altura. Células de parênquima axial seriado com 52,5 99,3 - $175 \mu \mathrm{m}$ de altura por 8,8 - 16,7 - 28,7 $\mu \mathrm{m}$ de largura. Quando em contato ocasional com vasos, as séries parenquimāticas são compos 
tas por um maior número de células, as quais são menos altas do que nas sēries apotraqueais.

Parênquima radial: Ocupando cerca de $22,2 \%$ do volume da madeira e constituído de raios fusiformes, normais; raios agregados e fusiona dos, ausentes. Tecido radial basicamente homogêneo; apenas com a pre sença de uma fileira de cēlulas pouco procumbentes, e tendentes a quadradas ou até fracamente eretas, na margem de muitos dos raios.

Raios uni-seriados muito escassos (1 - 3,3-5\% do total), de extremamente finos a muito finos $(7,5-13,2-20 \mu \mathrm{m})$, extrema mente baixos $(20-72,9-125 \mu \mathrm{m})$ e com $1-3,5-6$ células de alt $\underline{u}$ ra.

Raios multi-seriados, tri-seriados em sua maioria ( 60 $67,9-75 \%$ do total), menos frequentemente tetra-seriados ( 10 $15,7-22 \%)$ e bi-seriados $(9-13,1-19 \%)$; extremamente baixos $(130-276,4-515 \mu \mathrm{m})$, com 6 - 15 - 31 células de altura e finos $(15-37,3-50 \mu \mathrm{m})$.

Células envolventes, esclerosadas, latericuliformes e ole í feras, ausentes. Células cristalifferas são frequentes em raios; ocor rem mais comumente em cēlulas horizontais dispersas, frequentemente com duas cämaras, cada uma com um grande monocristal romboédrico de oxalato de cálcio.

Fibras: Tecido fibroso predominante, ocupando cerca de $54,8 \%$ do vo lume da madeira e constituído de fibras libriformes e fibrotraqueói des, não septados. Em fibrotraqueóides ocorrem numerosas pontuações areoladas e diminutas. Fibras gelatinosas ausentes.

Fibras curtas (735 - 1125 - $1362 \mu \mathrm{m})$, estreitas (11,3 $14,7-22,5 \mu \mathrm{m})$ e de paredes espessas $(4,3.5,2-6,9 \mu \mathrm{m})$.

outros caracteres: Canais secretores, tubos lacticíferos e taninife ros, lïber incluso, mäculas medulares e estratificação, ausentes.

Anēis de crescimento distintos, marcados por uma zona de fibras de diämetro um pouco menor e mais lignificadas, no tērmino do anel. Presença de inclusão orgânica com o aspecto de goma ou mucilagem em alguns poros. Presença de cristais, observada apenas em raios.

\section{ANALLISE DA ESTRUTURA ANATÖMICA}

A descrição anatōmica da madeira de Aspidosperma quebra cho-blanco Schlecht., realizada no presente trabalho, coincide, quan to aos caracteres mais conspícuos, com as referëncias de METCALFE \& CHALK (6) para o gênero. A presença de poros solitārios e raramente geminados, placas de perfuração simples e pequenas em relação ao diâa metro do vaso, parenquima axial tipicamente apotraqueal, e fibras com pontuações areoladas muito pequenas, são as características mais constantes e tîpicas na xilologia do gēnero. 
A afirmativa de heterogeneidade anatōmica em Aspidosperma sp., ressaltada por METCALFE \& CHALK (6) parece assentar-se princi palmente em características dos raios, diâmetro de poros e tipo de fibras.

No material estudado os raios mostram-se estreitos, no má ximo tetra-seriados, com alta predominância dos tri-seriados, e fra camente heterogêneos. A frequência de raios é levemente superior ao valor citado por TORTORELLI (10).

Quanto aos poros, encontrou-se frequência levemente maior e diâmetro médio significativamente menor do que em TORTORELLI (10). Este disparidade poderia sugerir a utilização neste trabalho de ma deira juvenil, o que não é correto. Encontrou-se, por outro lado, valores médios de comprimento de elementos vasculares e de fibras bem maiores do que os fornecidos por TORTORELLI (10). Estas diferen ças quantitativas podem ser justificadas pela procedencia do mate rial, e atribuīdas à variabilidade interna da espēcie.

As pontuações em fibras são areoladas e diminutas, mas pon tuações simples são tambēm encontradas. A presença de fibras libri formes e de fibrotraqueōides na madeira de quebracho-branco, è tam bēm reconhecida por TORTORELLI (9; 10), e vem a reafirmar a hetero geneidade anatômica, atribuída por METCALFE \& CHALK (6) ao gênero Aspidosperma.

\section{REFERENCIAS BIBLIOGRAFICAS}

1. COMISSAOO PANAMERICANA DE NORMAS TECNICAS. Descrição macroscópica, microscópica e geral da madeira - esquema I de recomendação. Colômbia, 1973. 19 p. (COPANT 30).

2. LATZINA, E. Index de la Flora Dendrolögica Argentina. Lizzoa, I: $95-211,1937$.

3. LOMBARDO, A. Flora arborea y arborescente del Uruguay. Montevi deo, Concejo Departamental de Montevideo, s/d. $151 \mathrm{p}$.

4. MARKGRAF, F. Apocināceas. In: REITZ, P.R. Flora I lustrada Catari nense. Itajai, 1968. $112 \mathrm{p}$.

5. MARZoCCA, A. Apocināceas. In: Las Plantas Cultivadas en Argenti na. Buenos Aires, Minist. Agric. e Granad., 1952. VII (120), 66 p.

6. RECORD, S.J. \& HESS, R.W. Timbers of the New World. New Haven, Yale University Press, 1949. $640 \mathrm{p}$.

7. REITZ, R.; KLEIN, R.M. \& REIS, A. Projeto Madeira do Rio Grande do Sul. Sellowia, 34-35: 1 - 525, 1983.

8. TORTORELLI, L.A. Maderas Argentinas. Buenos Aires, Imprensa da Universidade de Buenos Aires, 1940. Biblioteca Agronomica y Veterināria, Tomo III. $218 \mathrm{p}, \mathrm{i} 1$.

9. TORTORELLI, L.A. Maderas y bosques argentinos. Buenos Aires, ACME, 1956. $910 \mathrm{p}$.

Recebido em novembro, 1984; aceito em janeiro, 1985. 